\title{
Reducing Administrative Costs and Improving the Health Care System
}

\section{Citation}

Cutler, David, Elizabeth Wikler, and Peter Basch. 2012. "Reducing Administrative Costs and Improving the Health Care System." N Engl J Med 367 (20) (November 15): 1875-1878. doi:10.1056/nejmp1209711.

\section{Published Version}

doi:10.1056/nejmp1209711

\section{Permanent link}

http://nrs.harvard.edu/urn-3:HUL.InstRepos:26640484

\section{Terms of Use}

This article was downloaded from Harvard University's DASH repository, and is made available under the terms and conditions applicable to Other Posted Material, as set forth at http:// nrs.harvard.edu/urn-3:HUL.InstRepos:dash.current.terms-of-use\#LAA

\section{Share Your Story}

The Harvard community has made this article openly available.

Please share how this access benefits you. Submit a story.

Accessibility 
require treatment. CMS recognizes the importance of random variation and the need for actuarially stable populations in its Medicare Shared Savings Program, in which organizations cannot participate unless they serve at least 5000 beneficiaries. The bundled-payment initiative sets no such limits, and medium-sized hospitals typically have 100 to 200 cases for their highest-volume types of Medicare episodes. At these lower volumes, hospitals may have large year-to-year shifts in average spending for particular episode types owing to random variation in illness severity.

For example, our simulations showed that $25 \%$ of hospitals with 100 to 125 annual admissions for congestive heart failure would incur financial losses of at least $11 \%$ simply because their patients in the program's first year differ from those in the period used in setting their target prices. ${ }^{3}$ Another $25 \%$ of these hospitals would achieve financial gains of $6.1 \%$ or more. Such random variation in illness severity could overwhelm the effect of performance improvements in determining a hospital's shortterm financial outcomes making early wins and losses artifacts of variation rather than marks of true success or failure.

The Bundled Payments for Care Improvement Initiative has great potential to engage hospitals in clinical redesign and care coordination that could improve both care and efficiency. Hospitals already have incentives through Medicare's DRG payment system to make inpatient care more efficient, but few have invested in managing care after discharge. The bundled-payment initiative provides an opportunity for hospitals to gain experience with coordinating care across a continuum of services for discrete clinical conditions. Nonetheless, program managers must be vigilant to ensure that the financial incentives don't cause stinting on care or avoidance of high-risk patients. ${ }^{4}$

The success of the initiative will depend on whether it protects participating hospitals against losses resulting from both random and systematic variation in illness severity. Certain design features will make it much more attractive to hospitals, including risk adjustment, stop-loss protection for high-cost cases, an ability to exclude cases with highcost primary diagnoses from episode definitions, and so-called risk corridors that allow hospitals to share both gains and losses as they acclimate to the program. CMS has begun to discuss changes to the proposed financial model with applicants. If hospitals are confident that the program will financially reward successful clinical performance, many more will be willing to pursue the opportunities for care improvement that this program seeks to encourage.

Disclosure forms provided by the authors are available with the full text of this article at NEJM.org.

From the Heller School for Social Policy and Management, Brandeis University, Waltham, MA.

1. Welch WP. Bundled Medicare payment for acute and postacute care. Health Aff (Millwood) 1998;17:69-81.

2. RTI International. Post-acute care episodes: expanded analytic file data chart book: report to the Assistant Secretary of Planning and Evaluation, June 2011.

3. Tompkins C, Ritter G, Mechanic R, Perloff J. Chapman J. Analysis of financial risk and risk mitigation options in the Medicare Bundled Payment for Care Improvement program. Waltham, MA: Brandeis University, June 28, 2012 (http://sihp.brandeis.edu/ihs/ publications/Bundled\%20Payments $\% 20$ White\%20Paper.docx).

4. Mechanic RE, Altman SA. Payment reform options: episode payment is a good place to start. Health Aff (Millwood) 2009;28:w262w271.

DOI: $10.1056 / \mathrm{NEJMP1210823}$

Copyright @ 2012 Massachusetts Medical Society.

\title{
Reducing Administrative Costs and Improving the Health Care System
}

\author{
David Cutler, Ph.D., Elizabeth Wikler, B.A., and Peter Basch, M.D.
}

The average U.S. physician spends 43 minutes a day interacting with health plans about payment, dealing with formularies, and obtaining authorizations for procedures. $^{1}$ In addition, physi- cians' offices must hire coders, who spend their days translating clinical records into billing forms and submitting and monitoring reimbursements. The amount of time and money spent on admin- istrative tasks is one of the most frustrating aspects of modern medicine.

Indeed, for the system as a whole, administrative tasks are extremely costly. According to the 
Potential Savings for Health Care Providers from Reforms to Simplify Administrative Activities.:

\begin{tabular}{|c|c|c|}
\hline Solution & $\begin{array}{l}\text { Total Annual Savings } \\
\text { for Providers (\$) }\end{array}$ & Steps Needed to Achieve Savings \\
\hline Adoption of electronic transactions & 11.0 billion & $\begin{array}{l}\text { Implement the ACA, regulate the integration of billing and } \\
\text { administrative systems, encourage provider adoption }\end{array}$ \\
\hline $\begin{array}{l}\text { Integrated administrative and clinical } \\
\text { health systems }\end{array}$ & 2.1 billion & $\begin{array}{l}\text { Implement HITECH and expand certification criteria for elec- } \\
\text { tronic health records to include administrative provisions }\end{array}$ \\
\hline $\begin{array}{l}\text { National provider enrollment and } \\
\text { credentialing program }\end{array}$ & 0.9 billion & $\begin{array}{l}\text { Implement the ACA and promote regulations to standardize } \\
\text { and unify provider enrollment and credentialing sys- } \\
\text { tems across public and private entities }\end{array}$ \\
\hline Standardized reporting requirements & 0.1 billion & $\begin{array}{l}\text { Promote the HHS National Strategy for Quality Improve- } \\
\text { ment and support regulatory and legislative efforts to } \\
\text { standardize federal, state, and private-market reporting } \\
\text { requirements }\end{array}$ \\
\hline Stabilized enrollment in public programs & 1.8-2.9 billion & $\begin{array}{l}\text { Implement the ACA, promote federal and state legislation } \\
\text { to further streamline enrollment (including continuous } \\
\text { eligibility policies for adults), and endorse regulations } \\
\text { to coordinate benefits and networks across programs }\end{array}$ \\
\hline Widespread automation †广 & $2-6$ billion & $\begin{array}{l}\text { Implement the ACA, work to integrate with HITECH provi- } \\
\text { sions, and support public and private innovation }\end{array}$ \\
\hline Total savings accrued to providers & 17.9-23.0 billion & \\
\hline Savings per physician & 29,000 & \\
\hline
\end{tabular}

* The estimate for adoption of electronic transactions represents potential savings per year for the electronic processing of claim submissions, eligibility inquiries and requests, claims status requests, payment, and remittance transactions. It assumes uptake of $85 \%$. The amount of savings per physician is based on estimates of the total number of physicians in the United States in 2010, published by the Bureau of Labor Statistics. ACA denotes Affordable Care Act, HITECH Health Information Technology for Economic and Clinical Health Act, and HHS Health and Human Services. Data are from the U.S. Health Care Efficiency Index 2010 National Progress Report, the UnitedHealth Center for Health Reform and Modernization, the McKinsey Report: Overhauling the U.S. Healthcare Payment System 2007, and Milliman: Electronic Transaction Savings Opportunities for Physician Practices, 2006. $\uparrow$ This solution includes electronic adoption and automation of prior authorization.

Institute of Medicine (IOM), the United States spends \$361 billion annually on health care administration $^{2}$ - more than twice our total spending on heart disease and three times our spending on cancer. Also according to the IOM, fully half of these expenditures are unnecessary.

What can be done to reduce these costs? Though some argue that a single-payer system would eliminate many administrative expenses, that solution seems unlikely to be embraced in the United States. Nevertheless, administrative expenses are one area of health care in which large savings might be realized particularly rapidly (see table). The experience of other industries, along with the history of health care, shows how.

Standardization is a central factor in reducing administrative costs. The Federal Reserve lowered the administrative costs of banking by standardizing the way that computer systems from different banks communicated with one another. Similarly, Walmart made suppliers conform to its computer standards if they wanted to sell to the retail giant which led to enormous standardization of retail information systems.

In health care, only one organization has the sort of influence that Walmart and the Federal Reserve have in their domains: the federal government. But though attempts have been made to use federal policy to lead this sort of reform, they have so far come up short. The Health Insurance Portability and Accountability Act (HIPAA) of 1996 introduced mandatory standards for the electronic processing of common administrative transactions. Before HIPAA, more than 400 different formats were used for electronic health care claims; after HIPAA, there was just one. But HIPAA was not detailed enough, was not implemented rapidly enough, and allowed payers to request additional data from providers. The Department of Health and Human Services (DHHS) was slow to put out HIPAA regulations, and those it issued were suffi- 
ciently vague that payers and providers never agreed on a truly common standard. Granted, there was only one form, but payers' additional data requests, which varied both among payers and among health plans offered by a given payer, defeated the standardization effort. The result for providers was a continued mess, which discouraged the investment necessary to achieve electronic interchange.

Building on recent state-level and private-sector successes, the Affordable Care Act (ACA) took a second bite at the apple, and so far things are going better. The ACA requires the DHHS to set more detailed rules for processing administrative interactions. To improve compliance and strengthen enforcement, it imposes financial penalties on health plans that don't adopt these standardized procedures. Currently, providers are not required to adopt electronic transactions, but the hope is that the promise of increased efficiency will promote adoption. If ACA implementation goes as intended and widespread utilization and automation are achieved, providers could save about $\$ 11$ billion per year. ${ }^{3}$

There are areas that the ACA omitted that could also benefit from standardization. Credentialing and other systems that are used to establish contracts between providers and health plans are riddled with redundancy, with many organizations collecting virtually identical information from providers. The typical physician spends more than 3 hours annually submitting nearly 18 different credentialing forms, with staff spending an additional 20 hours. ${ }^{4}$ Some private-sector initiatives are working to streamline this pro- cess, but a coordinated, nationwide credentialing system that is employed across the public and private sectors could save nearly $\$ 1$ billion per year for providers. Further savings could be achieved if processes for establishing payerprovider contracts were also standardized and conducted electronically. ${ }^{5}$ The DHHS could mandate both changes under Section 10109 of the ACA, but so far it hasn't.

Standardization will not solve all the problems, however. Payers may be required to accept standard billing forms electronically, but the supplemental information required to approve a claim
There is a mechanism for doing that: the Health Information Technology for Economic and Clinical Health (HITECH) Act, which provides financial incentives for the acquisition of EHRs and specifies standards for the electronic transmission of clinical data; the secretary of health and human services could expand these criteria to include standards for electronic transmission of administrative data (such as billing information). Doing so could save providers as much as $\$ 2$ billion annually. ${ }^{5}$

Finally, coverage policies will need to be addressed. Currently, many Medicaid patients "churn"

\section{The possibilities for reducing administrative complexity are immense. The reforms we describe could save as much as $\$ 20$ billion annually for providers (roughly $\$ 29,000$ per physician), or $\$ 40$ billion annually for all stakeholders.}

may be costly to transmit. For example, a provider may bill for magnetic resonance imaging, but a payer's rules may stipulate that it will approve the charge only if the provider demonstrates that the procedure was medically necessary - for example, by submitting documentation of a working diagnosis with relevant test results and prescriptions. Such information is contained only in the medical record. To address this problem, the ACA will make the transmission of claims attachments more uniform; however, a more advanced approach would automatically integrate appropriate information from billing systems with the corresponding clinical information from electronic health records (EHRs). from one policy to another frequently. This movement adds additional expense to practice, since staff in providers' offices must determine which insurer is covering the patient each month and how much to collect from the insurer and the patient. If the federal government allowed and encouraged states to have an annual open-enrollment period, as private insurers do, coupled with 12-month continuous eligibility policies for nonelderly adults (giving them continuous access to Medicaid coverage even if family income fluctuates throughout the year), it could save providers nearly $\$ 3$ billion annually.

The possibilities for reducing administrative complexity are immense. The reforms we describe 
could save as much as $\$ 20$ billion annually for providers (roughly $\$ 29,000$ per physician), or $\$ 40$ billion annually for all stakeholders. And $\$ 2$ billion of these savings would accrue to the federal government - a relatively small but valuable contribution to reducing the deficit. For the individual physician, these savings could translate into more time and resources for direct patient care and therefore into improved professional satisfaction.

Unlike other proposals for reducing costs, such as restricting access to care, reducing administrative complexity could garner broad bipartisan support. The major stumbling block is that the constituency for administrative simplification is broad but diffuse. Achieving these reforms will require bold steps by policymakers to rise above the commotion surrounding health care re- form and push through changes that benefit the system as a whole. Only the federal government has the clout in health care to effect these changes. Thus, it may be necessary to establish a seniorlevel office in the DHHS focused solely on implementation and innovation in the realm of administrative simplification. Such an office would lead regulatory efforts in standardization and integration of billing with clinical records, advocate for federal and state legislation to reduce churning in public programs, and coordinate new regulations affecting administrative transactions.

The lack of this kind of leadership was a key obstacle to reducing administrative costs through HIPAA. Since the ACA's passage, the need is greater than ever. Doctors have thousands of reasons to hope that reforms are on the way.
Disclosure forms provided by the authors are available with the full text of this article at NEJM.org.

From the Department of Economics (D.C.) and the Ph.D. Program in Health Policy (E.W.), Harvard University, Cambridge, MA; and MedStar Health, Washington, DC (P.B.).

1. Casalino LP, Nicholson S, Gans DN, et al. What does it cost physician practices to interact with health insurance plans? Health Aff (Millwood) 2009;28:w533-w543.

2. Yong PL, Saunders RS, Olsen L, eds. The healthcare imperative: lowering costs and improving outcomes - workshop series summary. Washington, DC: National Academies Press, 2010.

3. US healthcare efficiency index: national progress report on healthcare efficiency. Nashville: Emodeon Business Services, 2010. 4. Pope $C$. The cost of administrative complexity: administrative intricacies add no value to health care - but the costs keep stacking up. MGMA Connex 2004;4:36-41.

5. Health care cost containment - how technology can cut red tape and simplify health care administration: working paper 2 . Minneapolis: UnitedHealth Center for Health Reform and Modernization, 2009.

DOI: 10.1056/NEJMp1209711

Copyright @ 2012 Massachusetts Medical Society.

\title{
The Reciprocity of Recognition - What Medicine Exposes about Self and Other
}

\author{
Rita Charon, M.D., Ph.D.
}

$M$ rs. N. announced triumphantly that she had become a U.S. citizen. Her husband - on whose English she depended, though she'd arrived from Albania 5 years earlier - said, "She took the test, and then she said the words with her hand like this." He put his hand over his heart. She grinned and blushed, seeming younger than her 50 years. When she answered one of my questions with a quick "79," I startled. Wait a minute, I thought, she doesn't speak English.

It was then that she shyly pointed to the hearing aid in her left ear. I remembered in a flash how hard the social worker and I had worked to arrange an ENT evaluation despite Mrs. N.'s lack of insurance and citizenship. I remembered the couple barging into my office some weeks later, terrified, crying, breathless, convinced that she was going to die. They had been told she needed an MRI to rule out a brain tumor, but they'd left the ENT clinic believing she had a brain tumor. Happily, I could reassure them otherwise. Now, hearing her say "79," I realized that she was hearing and on her way to speak- ing fluent English. I wasn't surprised to find her blood pressure normal, her dizzy spells and headaches gone.

Thanks to Mrs. N., I also saw something within myself that I treasure and cultivate and can sometimes claim: the leaningforward internist, the sleevesrolled-up doctor. With the ascendance of practice-based learning and its emphasis on selfassessment and lifelong learning, medicine has come to value the capacity of practice to provide a mirror not only for occasional selfreflection but for constant self- 